\title{
Electric LoAd Modelling OF THE POWER Transmission LINES AND COMPARISON WITH SCADA MEASUREMENTS
}

\author{
Vladimir Budimir \& Petar Marić
}
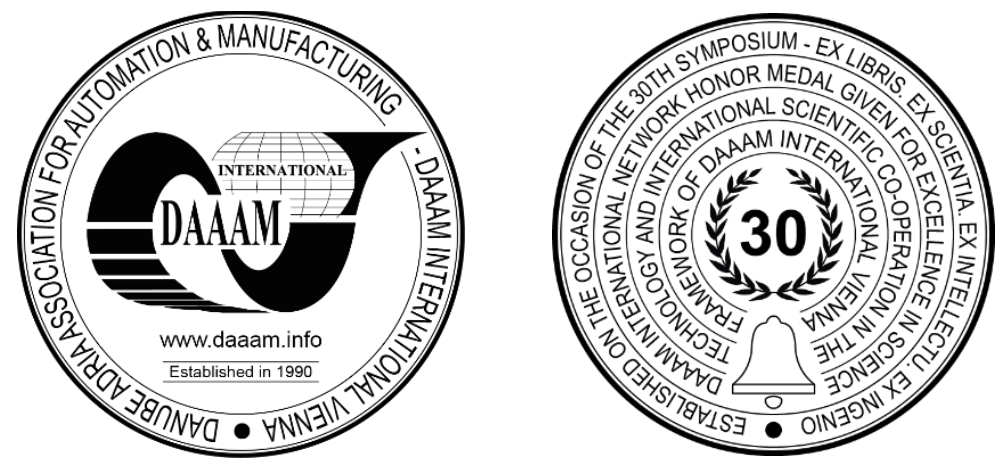

This Publication has to be referred as: Budimir, V[ladimir] \& Maric, P[etar] (2020). Electric Load Modelling of the Power Transmission Lines and Comaprison with SCADA Measurements, Proceedings of the 31st DAAAM International Symposium, pp.0758-0764, B. Katalinic (Ed.), Published by DAAAM International, ISBN 978-3-902734-29-7, ISSN 1726-9679, Vienna, Austria

DOI: $10.2507 / 31$ st.daaam.proceedings.105

\begin{abstract}
Due to the growing need for a global scale minimization of the greenhouse gasses in recent years, there is a high tendency for the renewable energy sources implementation. These circumstances allude to a different organization and optimization of existing power grids through inclusion of the new energy sources. Using the existing trends as the input parameters of the electric load from particular geographical area, detailed white box model of an electric consumption has been created. The simulation data from the model of the electric consumption have been analysed and compared with the SCADA measurements from the transmission grid. Through detailed analysis, the reliability indicators have been introduced for the future predictions of the important parameters in the transmission grid.
\end{abstract}

Keywords: energy sources; modelling; electric consumption; transmission grid; loadflow

\section{Introduction}

Energy efficiency is known as one of the most important and critical problems that scientific and research community needs to address in future years. Energy plays an important role in life of the ordinary people since it enables economies to expand, mobility and communication for the whole world and also enables basic needs such as lighting and heating application. Despite the potential benefits and uses of the energy in improving the quality of life for the whole planet, there are various negative impacts related with the extensive and inefficient energy use such as the increase of the greenhouse gasses and air pollution. In order to address these issues, large amount of effort has been invested to new technologies that should improve energy efficiency and reduce the amount of energy needed for the operation of the whole economies with the main goal of saving money and protecting the environment.

Transmission lines can be seen as the most important part of the electric power grids. Metaphorically, they are the arteries of electrical power systems. The system of well optimized, developed and high capacitance transmission line is able to easily move large quantities of electrical energy over long distances. In electrical power systems, the energy is moved from the plants or generating stations through transmission lines in to the distribution grid. The flow of active and reactive power is usually called load flow or power flow. 
Load flow analysis is one of the most important approaches associated with the investigation of the transmission grid operation, planning, modelling and fault diagnostics [1]. It is also a useful tool for determining the steady state operation properties of power grid. In this paper the radial transmission power grid has been simulated using white box approach with the specialized electric power simulation programs. The main reason behind the simulation and the load flow analysis is to gain quantitative and qualitative insights in to the electric load modelling on the junction between transmission and distribution grid. In addition a case study has been provided by determining how the load properties of a radial transmission power grid change by incorporating additional transformer stations in the direction of distribution grid.

At a time when electricity production is increasingly decentralized, small producers are on the rise, whose connection to the grid affects the security and reliability of the electricity system, as well as the quality of electricity supply. With the decentralized market and the erasure of borders between producers and consumers, there is a need for initial knowledge of the grid state of a certain area. This is possible by collecting data on the observed grid for daily occasions back several years. Data can be obtained from distribution companies, dispatch centres and transmission system operators. In this way, you get an insight into the structure of the grid, characteristics, power flows, voltage conditions and the weaknesses and shortcomings of the power grid.

Various grid analysis tools are available to future investors who, using data from the grid, can model the connection of a new production unit or consumption in the form of a new industry [2] [3]. Both production and consumption, depending on the type and performance and accessories, affect the condition of the grid. E.g. consumption can be capacitive or inductive and, depending on that, can additionally load the grid with reactive power, which requires additional investment in the form of reactive power compensators. And if, for example, it is a solar or wind power plant, the connection of which can lead to asymmetry of voltage and current, as well as increased load in the grid and increased losses. These are all things that the designer will take into account, study and design in detail, but one can initially do the calculation of power flows in the model using real SCADA data, which will greatly reduce the time spent in choosing the optimal grid connection.

The aim of this paper is to consider the situation on case study grid, with data taken from the competent SCADA service. Then it is necessary to make a model of the observation part of the transmission grid and compare the results of the model and SCADA data.

\section{Case study radial transmission grid}

The operational area of larger transmission system includes radial subsystem of six $110 \mathrm{kV}$ transmission lines. This case study transmission ring is a part of the large national $110 \mathrm{kV}$ voltage transmission grid [4].

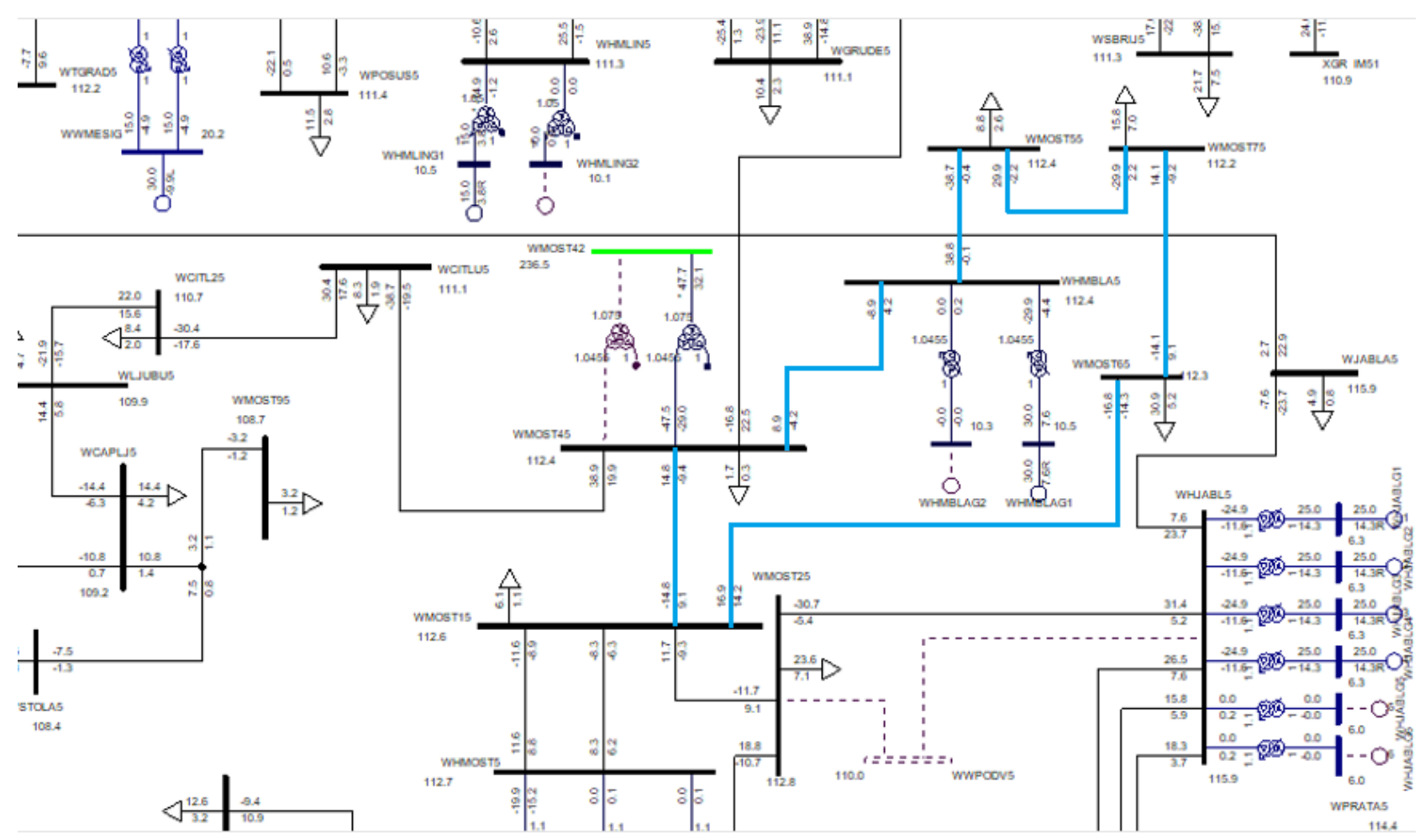

Fig. 1. Winter peak of the $110 \mathrm{kV}$ case study radial transmission grid (blue) [4] 
It consists of the following, interconnected $110 \mathrm{kV}$ transmission lines:

- switchyard WMOST15 - SS (substation) WMOST45,

- SS WMOST45 - HPP (hydro power plant) WHMBLA5,

- HPP WHMBLA5 - SS WMOST55,

- SS WMOST55 - SS WMOST75,

- SS WMOST75 - SS WMOST65 and SS WMOST65 - switchyard WMOST15.

As a case for observing the maximum load on this radial transmission system, SCADA data is used for the so-called winter peak which occurred on January 15, 2020. The exchange between hubs i.e. substations as well as transmission line loads for a given period is shown. Also, it is necessary to check the availability of this system when it comes to maximum loads. In this way, we come to predict future scenarios that include an increase in consumption caused by any event, and gain knowledge about the necessary future investments in the security and reliability of transmission systems in a particular area. So, we can detect the weak points of the grid, whether it is the power of transformation or the need to relieve the transmission system with new transmission lines.

\begin{tabular}{|l|c|c|c|c|c|c|}
\hline SUBSTATION & WMOST15 & WMOST45 & WMBLA5 & WMOST55 & WMOST65 & WMOST75 \\
\hline WMOST15 & $\bullet$ & -14.8 & & & & \\
\hline WMOST45 & 14.8 & $\bullet$ & 8.9 & & & \\
\hline WMBLA5 & & -8.9 & $\bullet$ & 38.8 & & 29.9 \\
\hline WMOST55 & & & & $\bullet$ & & -14.1 \\
\hline WMOST65 & -16.8 & & & & $\bullet$ & $\bullet$ \\
\hline WMOST75 & & & & & 14.1 & $\bullet$ \\
\hline
\end{tabular}

Table 1. Load flow during winter peak on January $15^{\text {th }} 2020$

Given that during January the maximum consumption of electricity occurs on the case study grid, where it can be witnessed the maximum production of electricity in nearby hydropower plants, it is necessary to take into account the data on the availability of elements of the observed radial grid. During January, the maximum loads of transmission lines and associated equipment occur, so it is necessary to review the availability of elements of the observed grid during that period. Given that the entire radial case study $110 \mathrm{kV}$ grid is under significant load, it is necessary to read the reports of the competent dispatch centre and see if there are any failures that could be prevented in the future. This is important if the observed area plans to build new consumption objects, as well as plants producing electricity from renewable energy sources which in a special way affect the grid. In addition, this case study includes a hydroelectric power plant in the system, which may be out of operation due to regular annual maintenance. The competent dispatch centre records the number and duration of active and transient failures as well as the number and duration of forced, planned and unplanned failures. For the three of the six case study transmission lines, in January 2020, unavailability was recorded only due to planned disconnections due to overhaul or maintenance of equipment.

\begin{tabular}{|l|c|c|c|}
\hline TRANSMISSION LINE & $\begin{array}{l}\text { Voltage } \\
{[\mathrm{kV}]}\end{array}$ & $\begin{array}{l}\text { Number of planned } \\
\text { disconnections }\end{array}$ & $\begin{array}{l}\text { Duration of planned } \\
\text { disconnections [min] }\end{array}$ \\
\hline WMOST15- WMOST45 & 110 & 4 & 1117 \\
\hline WMOST45- WHMBLA5 & 110 & 5 & 1685 \\
\hline WMBLA5- WMOST55 & 110 & 2 & 637 \\
\hline WMOST55- WMOST75 & 110 & - & - \\
\hline WMOST75-WMOST65 & 110 & - & - \\
\hline WMOST75- WMOST15 & 110 & - & - \\
\hline
\end{tabular}

Table 2. Transmission line downtime statistics (January 2020)

As it can be seen from statistics, the only unavailability of the observed transmission lines occurred during the planned outages related to regular maintenance, so we can conclude that the observed grid withstands peak loads well during the winter. 


\section{Electric load modelling}

The aim of this paper is to make a model of the existing part of the grid whose characteristics were recorded at a specific occasion on the screen of the dispatch centre or SCADA service. In this case it is the maximum grid load in January 2020 during the winter increase in consumption. The model done in NEPLAN [5] simulation tool should be compared with real circumstances and point out possible modifications of the case study grid.

\subsection{Case study}

The model calculation requires data on the observed transmission lines such as conductor type, transmission line length, line constants, voltage level, etc. [6][7]. When designing transmission lines, catalogue values of line constants are used, which change during the service life and must be regularly measured and checked to adjust protective devices.

\begin{tabular}{|l|c|c|c|c|c|c|c|}
\hline Conductor type & In $[\mathbf{A}]$ & $\begin{array}{c}\mathbf{R 1} \\
{[\mathbf{o h m} / \mathbf{k m}]}\end{array}$ & $\mathbf{X 1}[\mathbf{o h m} / \mathbf{k m}]$ & $\begin{array}{c}\mathbf{L 1} \\
{[\mathbf{m H} / \mathbf{k m}]}\end{array}$ & $\begin{array}{c}\mathbf{R 0} \\
{[\mathbf{o h m} / \mathbf{k m}]}\end{array}$ & $\begin{array}{c}\mathbf{X 0} \\
{[\mathbf{o h m} / \mathbf{k m}]}\end{array}$ & $\begin{array}{c}\mathbf{L 0} \\
{[\mathbf{m H} / \mathbf{k m}]}\end{array}$ \\
\hline AlFe 1 240 40 & 645 & 0,1190 & 0,4050 & 1,2890 & 0,3297 & 1,2648 & 4,0260 \\
\hline AlFe 2 240 40 & 1290 & 0,0483 & 0,3159 & 1,0055 & 0,1700 & 1,0400 & 3,3104 \\
\hline AlFe 1 150 25 & 470 & 0,1941 & 0,4217 & 1,3423 & 0,5823 & 1,4740 & 4,6919 \\
\hline Cu 1 150 & 510 & 0,1229 & 0,4610 & 1,4674 & 0,3687 & 1,5600 & 4,9656 \\
\hline AlFe 1 120 & 410 & 0,2370 & 0,4100 & 1,3051 & 0,7100 & 1,6400 & 5,2203 \\
\hline
\end{tabular}

Table 3. Line constants catalogue values for the type of conductor

Through the known inductance of the line it is possible to calculate the line capacity. According to the theory of electricity transmission, the product of the driving capacity $\mathrm{C}_{1}$ and the driving inductance $\mathrm{L}_{1}$ per unit length of the line is equal to the reciprocal of the square of the speed of light [8]:

$$
C_{1} L_{1}=\frac{1}{c^{2}}
$$

Where $\mathrm{c}=3 \cdot 10^{8}[\mathrm{~m} / \mathrm{s}]$.

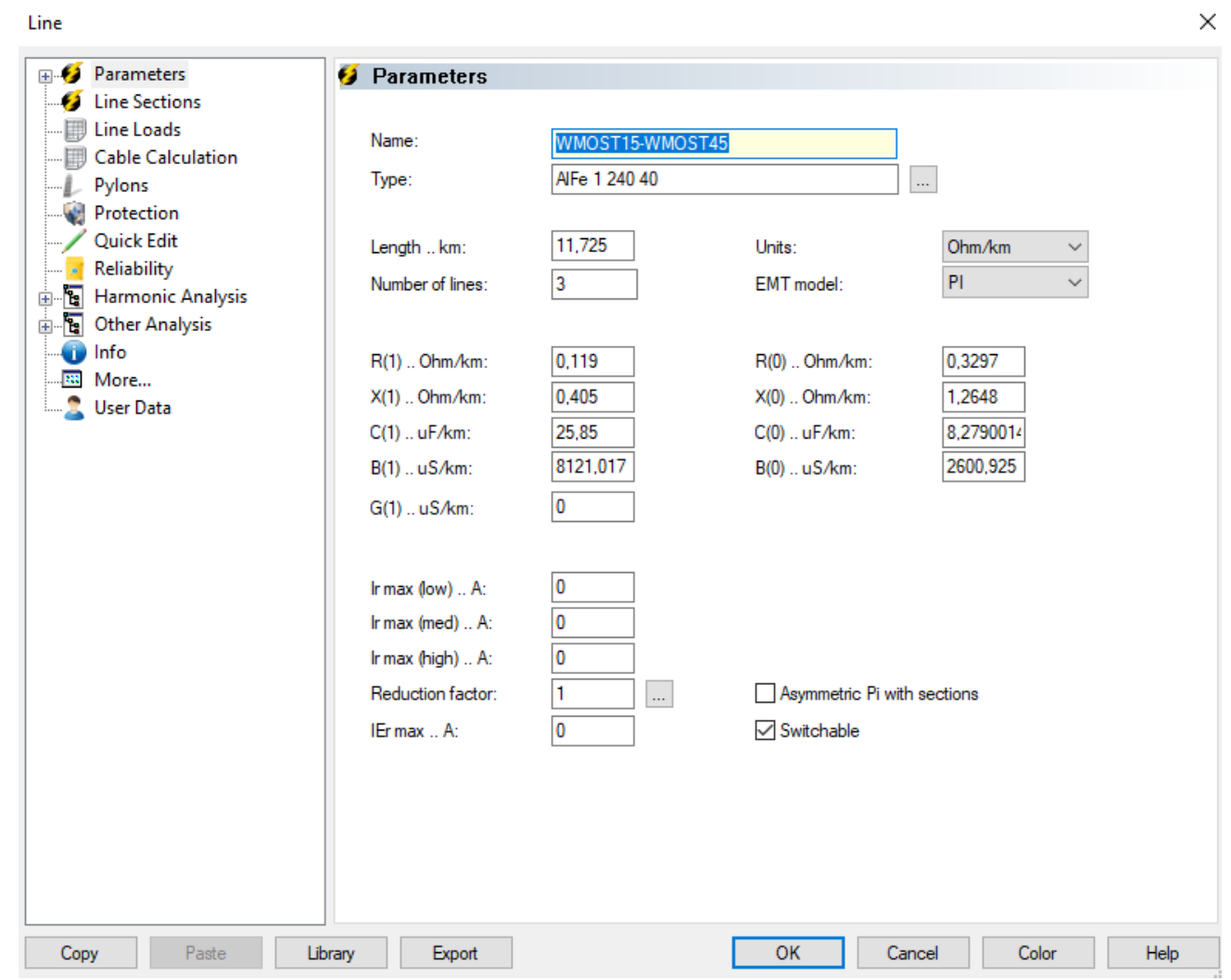

Fig. 2. Line parameters of the WMOST15-WMOST45 $110 \mathrm{kV}$ line [5] 


\section{Results overview and discussion}

Because the observed grid is only a small part of a large national transmission system, ie the data is a micro-fragment that is not without other grid influences, feeders (F1-F4) that simulate the surrounding grid outside the case study transmission system are inserted.

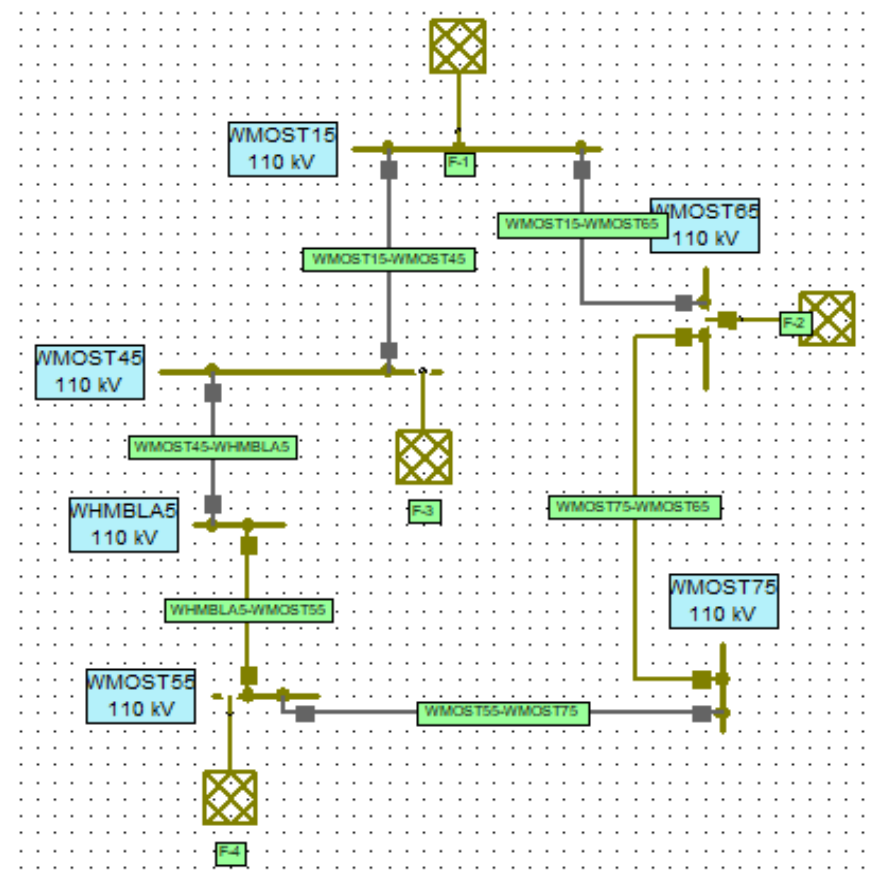

Fig. 3. Case study radial $110 \mathrm{kV}$ transmission grid in NEPLAN [5]

What needs to be analyzed are the voltage conditions on the busbars (nodes) as well as the loadflow. Given the results, some future improvements can be given in the form of a new $110 \mathrm{kV}$ connection, which would further relieve the existing grid. The possibility of connecting some larger additional industrial consumption can be considered, as well as the possibility of supplying this part of the grid with some renewable form of energy.

\begin{tabular}{|l|c|c|c|}
\hline NODE NAME & $\mathbf{U}[\mathbf{k V}]$ & $\mathbf{u}[\%]$ & $\mathbf{U}_{\text {[angle }}{ }^{\circ}$ ] \\
\hline WHMBLA5 & 113,17 & 102,88 & $-0,1$ \\
\hline WMOST15 & 112,20 & 102,00 & 0 \\
\hline WMOST45 & 113,19 & 102,90 & 0 \\
\hline WMOST55 & 112,31 & 102,10 & 0 \\
\hline WMOST65 & 112,53 & 102,30 & 0 \\
\hline WMOST75 & 114,76 & 104,32 & $-0,4$ \\
\hline
\end{tabular}

Table 4. Model nodes voltages

\begin{tabular}{|l|l|c|c|c|c|}
\hline NODE NAME & ELEMENT NAME & P [MW] & I [kA] & I angle [ $\left.{ }^{\circ}\right]$ & P loss [MW] \\
\hline WHMBLA5 & WMOST45-WHMBLA5 & $-8,537$ & 0,721 & 91,7 & 0,0029 \\
\hline WHMBLA5 & WHMBLA5-WMOTST55 & 4,357 & 0,721 & $-88,3$ & 0,1168 \\
\hline WMOST15 & WMOST15-WMOST45 & $-14,722$ & 9,342 & 89.7 & 16,1217 \\
\hline WMOST15 & WMOST15-WMOST65 & 16,212 & 9,15 & 89,5 & 14,4062 \\
\hline WMOST45 & WMOST45-WHMBLA5 & 8,729 & 2,742 & 88,5 & 0,469 \\
\hline WMOST45 & WMOST15-WMOST45 & 14,722 & 9,342 & 89,7 & 16,1217 \\
\hline WMOST55 & WMOST55-WMOST75 & 48,561 & 9,158 & 88,4 & 12,3999 \\
\hline WMOST55 & WHMBLA5-WMOST55 & 29,951 & 2,748 & 86,2 & 0,3909 \\
\hline WMOST65 & WMOST15-WMOST65 & $-14,468$ & 2,241 & $-92,7$ & 4,1385 \\
\hline WMOST65 & WMOST75-WMOST65 & 14,468 & 2,241 & 87,3 & 0,1195 \\
\hline WMOST75 & WMOST55-WMOST75 & $-29,907$ & 3,789 & $-90,9$ & 5,3541 \\
\hline WMOST75 & WMOST75-WMOST65 & 29,907 & 3,789 & 89,1 & 1,1557 \\
\hline
\end{tabular}

Table 5. Model loadflow data 


\subsection{Model comparison with SCADA}

The tool used has built-in functions related to the types of protection of the power system and the option of entering electrical parameters to adjust the remote and differential protection of lines and transformers. The differences between the values of SCADA downloaded data and the model are most obvious in the relationship between node voltage and transmission line power. The actual grid is largely complex and balanced, as part of a national and international transmission system, so it is realistic to expect certain deviations of a model that observes only a small fragment of a large system. Compared to the bus voltage, we witness slightly higher voltage values. As for power flows, it can be seen that the model values (Table 5.) are almost equal to the SCADA data for January 15, 2020 (Table 1.) with some additional flows. Comparison charts are shown in Fig.4. and Fig.5.

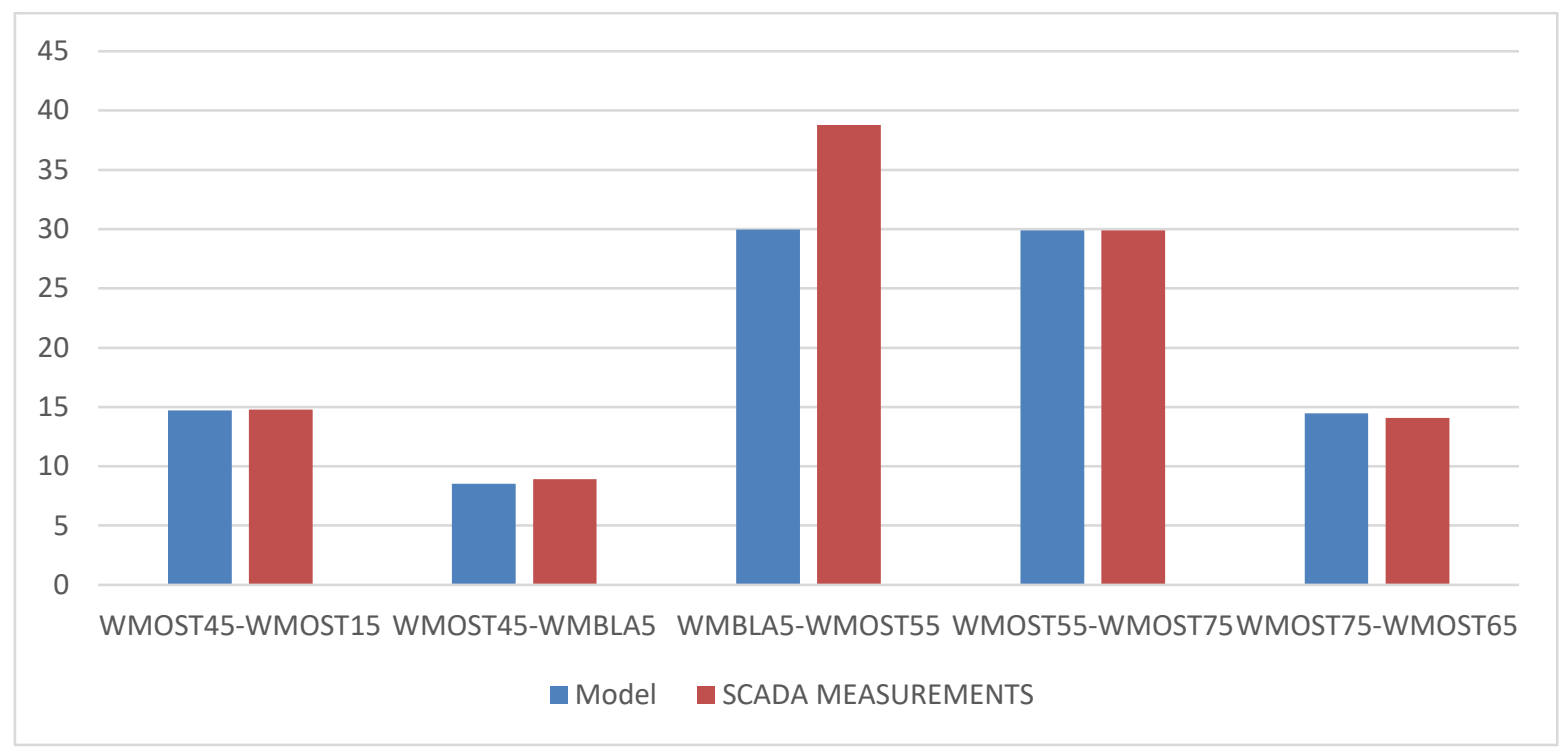

Fig.4. Load flow comparison

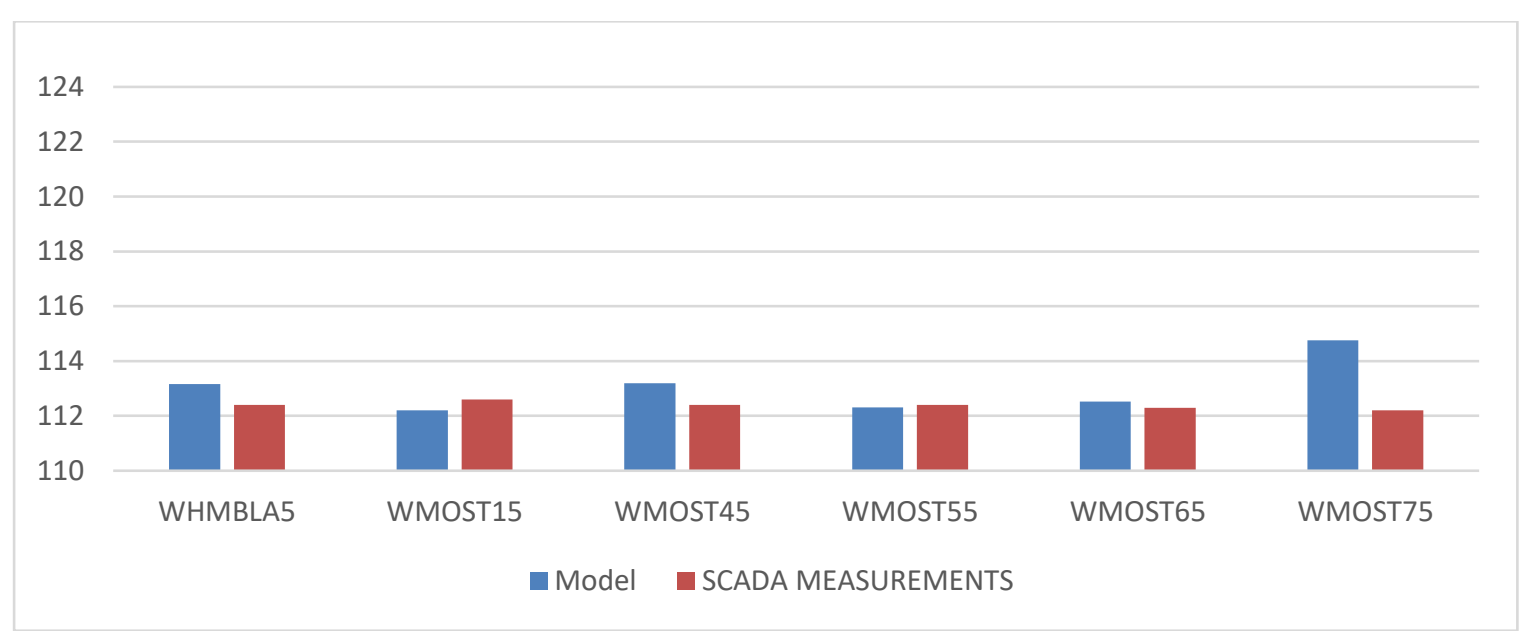

Fig.5. Node (busbar) voltages comparison

\section{Conclusion}

A comparison of the model and the real-time state of the radial grid showed that with the basic grid parameters a very good model can be obtained which can then be used for grid model changes in the form of adding new elements such as power plants, new transmission lines, substations and additional grid load. The aim of the study was to show that the grid can be simulated using data on transmission lines such as conductor type, transmission line constants, transmission line length, load and voltage level. In addition to these basic parameters, the substance and analysis of this paper can be expanded by entering data on the type of transformers in substations, by inserting the types of protection of transmission lines and transformers and their adjustment. In addition to the catalogue values of line constants, some future research may use measured values that change over time and need to be constantly monitored. 
This paper also showed that there is a good response from the competent grid monitoring and management services that can provide real-time data on the part of the grid in which one want to invest or which needs to be improved for infrastructure needs. A very simple way is to come up with a model that can then be modified according to the needs of investors and local infrastructure projects to get some initial information on the impact of the investment on the grid and to get an introduction on the additional cost of removing any negative impacts.

\section{Acknowledgement}

The authors thank engineering colleagues from Elektroprijenos $\mathrm{BiH}$ and Independent System Operator in Bosnia and Herzegovina (NOS $\mathrm{BiH}$ ) for providing the data needed to write this paper.

\section{References}

[1] Hlaing, Ya Min Su, and Ze Ya Aung. "Performance Analysis on Transmission Line for Improvement of Load Flow." Advanced Materials Research 433-440 (January 2012): 7208-12.

[2] Rupa, J., \& Ganesh, S. (2014). Power Flow Analysis for Radial Distribution System Using Backward/Forward Sweep Method. International Journal of Electrical and Computer Engineering, 8, 1621-1625.

[3] Afolabi, O.A., Ali, W.H., Cofie, P., Fuller, J., Obiomon, P. And Kolawole, E.S. (2015),,Analysis of the Load Flow Problem in Power System Planning Studies“, Energy and Power Engineering , 7, 509-523

[4] NOS BiH (2020)“Indikativni Plan Razvoja Proizvodnje 2021-2030“, Bosnia and Herzegovina

[5] NEPLAN - Power System Analysis, NEPLAN AG, Zurich, Switzerland

[6] Saadat, H.: Power System Analysis. WCB McGraw-Hill, New York, 1999.

[7] Jozsa, L.: Parametri nadzemnih vodova, University of Josip Juraj Strossmayera in Osijek, Faculty of Electrical Engineering Osijek, Osijek, 2006

[8] Brkić, N.: Mehanički proračun vodiča, University of Rijeka, Faculty of Technical Studies, Rijeka 2015. 